\title{
The role of red blood cells exchange in Sickle cell disease in a patient with COVID-19 infection and pulmonary infiltrates. (Case report and mini-review)
}

\author{
Lina Okar ${ }^{1,1}$, Maya aldeeb ${ }^{1}$, and Mohamed yassin ${ }^{1}$ \\ ${ }^{1}$ Hamad Medical Corporation
}

October 1, 2020

\begin{abstract}
COVID-19 related pneumonia overlaps with ACS, one of the most common acute presentations in SCD patients. We present a case of 22-year-old SCD patient presented to the emergency department with mild respiratory symptoms turned out to be COVID-19 positive and received red blood cell exchange to avoid the possibility of deterioration.
\end{abstract}

\section{Introduction:}

COVID-19 also known as severe acute respiratory syndrome coronavirus 2 (SARS-COV2) is the novel virus that caused the latest pandemic in the world. The most serious presentation of this virus was acute respiratory distress syndrome (ARDS) which has high mortality rate. Elderly patient and those with multiple co-morbidities have been categorized as high-risk group for developing serious complication from COVID-19 infection[1].

SCD is one of the most common hemoglobinopathies worldwide, it affects the shape of Red Blood Cells (RBCs) which leads to several clinical manifestations. Complications might be acute or chronic, the most important and common acute complications are Vaso-occlusive crisis (VOC) and Acute Chest Syndrome (ACS)[2]. Respiratory infections are considered an important trigger for ACS[3]. The impact of COVID-19 infection in SCD patients is still not clear and data is conflicting. However, some experiences suggested low mortality and morbidity rate in SCD patients with COVID-19 infection[4]. previously published researches mentioned the overlap between COVID-19 pneumonia and ACS[1] which we believed rises a challenge for physician, thus we recommend that those patients should monitored closely as deterioration in their clinical status was prescribed in multiple case reports[5]. The definitive management plan in this situation is not defined clearly till now. Whether applying early red blood cells exchange can prevent further deterioration is still a question that need to be answered.

\section{Case presentation:}

A 22-year-old male presented to the hospital with history of fever, sore throat, mild nonproductive cough, generalized body ache, chest pain, fatigue, and decreased appetite for three days. Positive sick contact history with an a positive COVID-19 case, no recent travel. His past medical history was remarkable for non-transfusion dependent Sickle cell disease taking Hydroxyurea $500 \mathrm{mg}$ daily, no previous surgeries, previous recurrent painful crisis most of them did not require hospital admission and presented as generalized pain, pain in the right arm and left hip which appeared to be avascular necrosis, last painful crisis was 7 months before as lower limb pain relieved with tramadol . Primary investigations including Laboratory tests, Nasopharyngeal swab for COVID-19 PCR, chest Xray were performed and the result were as following: Table.1 
To this point the patient differential diagnosis was: Acute chest syndrome triggered with COVDI-19 infection or viral pneumonitis. He admitted to the intensive care unit (ICU) after considering him as high risk for COVID-19 complication. The decision was made to do red blood cells exchange early in the course of the infection to avoid possible deterioration in his case and the need of intubation. Upon admission to the ICU his vital were as following: Temperature 36.4, Heart rate $69 / \mathrm{min}$, Respiratory rate $20 / \mathrm{min}$, Blood pressure $117 / 59 \mathrm{mmHg}$, maintain oxygen saturation of $96 \%$ on room air, he didn't require any oxygen supplementation in ICU. He was on the following medications: Lopinavir/ Ritonavir (Kaletra) 200/50 mg for two days then stopped and cefuroxime $1.5 \mathrm{~g}$ daily for 7 days, Hydroxyurea $500 \mathrm{mg}$ daily, enoxaparin 40 mg SC as thrombosis prophylaxis though he had Thrombocytopenia which is relative contraindication as well he is high risk of thromboembolic in SCD. Plasma exchange with 6 units PRBCs was done on the second day of hospital admission without any complications. He stayed in the ICU for 4 days for observation then transferred to the ward, during ICU admission no deterioration was happened, in the ward repeated Chest X-ray was normal. After 6 days in the ward without any deterioration in his clinical course with resolving of respiratory symptoms the patient was discharged to a quarantine facility.

\section{Discussion:}

Coronavirus is the novel virus responsible for the latest pandemic that declared by World Health Organization WHO on March 11,2019. Taking a good history to define the risk of infection is critical as patient might be asymptomatic. However, symptomatic patients may present with fever, dyspnea, fever, fatigue, and generalized muscle ache. Other non-typical symptoms like gastrointestinal were also reported[6]. Severity of the disease differs among affected patients, elderly, patients with co-morbidities like hypertension, diabetes and cardiovascular diseases are at more risk for complication and worse clinical course than normal population[7].

Sickle cell disease (SCD) is an inherited hemoglobinopathy with main characteristic being the presence of Hemoglobin $\mathrm{S}(\mathrm{HbS})$. The inheritance might be in homozygous or heterozygous form with a disease severity that differs accordingly. This hemoglobin cause deformity in the structure of Red Blood Cells (RBCs) changing them to sickle-shaped, rigid as well dysfunctional RBCs. Clinical manifestations are Vaso-occlusive crisis (VOC), intra- and extra- vascular hemolytic anemia [2]. Complication of SCD can be categorized into acute and chronic.

Acute complications include: Acute chest syndrome (ACS), Vaso-occlusive crisis (VOC), hepatobiliary complications, stroke, splenic sequestration, priapism, acute anemia, and fever[8]. Chronic complications are pulmonary hypertension, hepatic iron overload, kidney disease, avascular necrosis, retinopathy, and legs ulcer [7,9-12]. Among the acute complications, the most common are VOC and ACS. VOC are episodes of severe pain due to microvascular occlusion with erythrocytes and leukocytes, thus preventing blood flow and causing organ ischemia. ACS is common lung insult in SCD patients, known as newly pulmonary infiltrate due to alveolar consolidation affecting one lung segment at least, in it is severe form it is similar to the acute respiratory distress syndrome (ARDS), along with the radiological findings, patients usually present with fever, chest pain, shortness of breath, cough and wheezing. Its considered the second most common cause of hospitalization and the main reason behind intensive care unit admission as well early death among those patients[3]. There are three previously mentioned causes of ACS; first: pulmonary infection, second: bone marrow fat embolization and thirdly, intra-vascular pulmonary sequestration. Among those causes, pulmonary infections are the most common one and it is usually due to community-acquired pathogen that cause over inflammatory response instead of mild upper respiratory picture[3]. The National Acute Chest Syndrome Study published by Vichinsky et al to defined the causes of ACS, their study showed that infections are the main cause with atypical bacteria and viruses being the major causes, and despite the splenic dysfunction in SCD encapsulated bacteria were rarely isolated[13].

Patients with hemoglobinopathies are considered high risk for developing severe complication from COVID19 infection as per the Thalassemia international federation[14].However, no strong evidence is available, and it is not known in COVID-19 infection really increase the morbidity and mortality in SCD patients or not[4]. The overlap between the ACS and COVID-19 pneumonia has been described [15]. Thus, taking a final decision in this regard is hard because of the conflict in literature and variance of COVID-19 clinical 
course among SCD population, we summarize all previously published data in Table 2 .

As we notice from the table above few published cases described the use of RBCs exchange to manage ACS in SCD patients. Whenever RBCs exchange was used it was because the patients deteriorated, interestingly all of them improved after the exchange that is why we should raise the following question " is it necessary to leave this choice as a rescue option?" . The most similar published case to our patient was published by and described the role of early RBCs exchange in preventing further deterioration in their patient as once oxygen requirement started to increase RBCs exchange offered rather than simple transfusion or other medications[15]. The difference in our case is that we chose to offer our patient RBCs exchange even when he was stable due to the overlapping between ACS and COVID-19 pneumonia and by weighing the benefit and risk we believe that giving him RBCs exchange played an important role in alleviating the infection course as well the need of ICU admission and possible intubation.

Both pneumonia and acute chest syndrome are life-threatening condition. Red blood cell exchange is well known method to treat ACS and there are published data about using it in case of severe COVID-19 pneumonia, mostly after deterioration $[1,5,15]$. Here, we present the first case report for SCD patient infected with COVID-19 who received red blood cells exchange immediately after admission to avoid the deterioration and need of intubation giving him the benefit of doubt. We think offering RBCs exchange for patients with SCD and COVID-19 pneumonia upon diagnosis may have major benefits such as, avoiding ICU admission and intubation.

\section{Conclusion:}

With the latest pandemic due to COVID-19 infection a lot of patients were vulnerable and at risk of developing severe and fatal complications. Patients with SCD suffer from multiple acute and chronic complications. The exact clinical course of COVID-19 infection in those patients is not yet final and conflicting data are available. However, delaying appropriate management may carry an increased risk for intubation and mortality. We recommend that physicians should keep a low threshold for admitting SCD patients in whom they suspect COVID-19 infection and to monitor them closely as well provide RBCs exchange initially in the disease course to give them the benefit of doubt. More research is needed to reach a high evidence regarding the management plan.

\section{Acknowledgment}

We would like to acknowledge the Hematology section/ oncology department, Intensive care unit as well as Family medicine residency program at Hamad Medical Corporation for their support.

\section{Statement of Ethics}

Consent was obtained from the patients.

Case approved by HMC Medical Research center

\section{Declaration of interest}

The authors report no conflicts of interest.

\section{Authors contribution:}

All authors contributed equally in writing the manuscript.

\section{References:}

[1] Hussain FA, Njoku FU, Saraf SL, Molokie RE, Gordeuk VR, Han J. COVID-19 infection in patients with sickle cell disease. Br J Haematol 2020;189:851-2. https://doi.org/10.1111/bjh.16734.

[2] Pinto VM, Balocco M, Quintino S, Forni GL. Sickle cell disease: a review for the internist. Intern Emerg Med 2019;14:1051-64. https://doi.org/10.1007/s11739-019-02160-x.

[3] Gladwin MT, Vichinsky E. T 2254. Sci York 2009:2254-65. https://doi.org/10.1164/rccm.201111-2082CI. 
[4] Ramachandran P, Perisetti A, Kathirvelu B, Gajendran M, Ghanta S, Onukogu I, et al. Low morbidity and mortality with COVID-19 in sickle cell disease: A single center experience. EJHaem 2020:jha2.87. https://doi.org/10.1002/jha2.87.

[5] Beerkens F, John M, Puliafito B, Corbett V, Edwards C, Tremblay D. COVID-19 pneumonia as a cause of acute chest syndrome in an adult sickle cell patient. Am J Hematol 2020;95:E154-6. https://doi.org/10.1002/ajh.25809.

[6] Down B, Kulkarni S, Khan AHA, Barker B, Tang I. Novel coronavirus (COVID-19) infection: What a doctor on the frontline needs to know. Ann Med Surg 2020;55:24-9. https://doi.org/10.1016/j.amsu.2020.05.014.

[7] Soliman AT, Prabhakaran Nair A, Al Masalamani MS, De Sanctis V, Abu Khattab MA, Alsaud AE, et al. Prevalence, clinical manifestations, and biochemical data of type 2 diabetes mellitus versus nondiabetic symptomatic patients with COVID-19: A comparative study. Acta Biomed 2020;91:e2020010. https://doi.org/10.23750/abm.v91i3.10214.

[8] Wali Y, Kini V, Yassin MA. Distribution of sickle cell disease and assessment of risk factors based on transcranial Doppler values in the Gulf region. Hematol (United Kingdom) 2020;25:55-62. https://doi.org/10.1080/16078454.2020.1714113.

[9] Yassin M, Soliman A, De Sanctis V, Nashwan A, Abusamaan S, Moustafa A, et al. Liver iron content (LIC) in adults with sickle cell disease (SCD): Correlation with serum ferritin and liver enzymes concentrations in transfusion dependent (TD-SCD) and non-transfusion dependent (NT-SCD) patients. Mediterr J Hematol Infect Dis 2017;9. https://doi.org/10.4084/mjhid.2017.037.

[10] Yassin MA, Soliman AT, de Sanctis V, Abdula MAJ, Riaz LM, Ghori FF, et al. Statural growth and prevalence of endocrinopathies in relation to liver iron content (LIC) in adult patients with beta thalassemia major (BTM) and sickle cell disease (SCD). Acta Biomed 2018;89:33-40. https://doi.org/10.23750/abm.v89i2-S.7085.

[11] Shier A, Abdelrazek M, Soliman A, De Sanctis V, Elsayed A, Abdulla M, et al. Short-Term Outcome and MRI Changes in Three Adult Patients with Sickle Cell Disease and Aseptic Osteonecrosis after Treatment with Hyperbaric Oxygen Therapy: A Preliminary Report. Case Rep Oncol 2020;13:365-72. https://doi.org/10.1159/000506330.

[12] Abdelmahmuod E, Yassin MA, Ahmed M, Ali E. The Relationship Between Sickle Cell Disease and Sudden Onset Sensorineural Deafness. Cureus 2020. https://doi.org/10.7759/cureus.9413.

[13] Vichinsky EP, Neumayr LD, Earles AN, Williams R, Lennette ET, Dean D, et al. Causes and outcomes of the acute chest syndrome in sickle cell disease. N Engl J Med 2000;342:1855-65. https://doi.org/10.1056/NEJM200006223422502.

[14] Farmakis D, Giakoumis A, Cannon L, Angastiniotis M, Eleftheriou A. COVID-19 and thalassaemia: A position statement of the Thalassaemia International Federation. Eur J Haematol 2020:1-9. https://doi.org/10.1111/ejh.13476.

[15] Allison D, Campbell-Lee S, Crane J, Vidanovic V, Webb S, Fraidenburg D, et al. Red blood cell exchange to avoid intubating a COVID-19 positive patient with sickle cell disease? J Clin Apher 2020;35:378-81. https://doi.org/10.1002/jca.21809.

[16] Hussain FA, Njoku FU, Saraf SL, Molokie RE, Gordeuk VR, Han J. COVID-19 infection in patients with sickle cell disease. Br J Haematol 2020;189:851-2. https://doi.org/10.1111/bjh.16734.

[17] Nur E, Gaartman AE, van Tuijn CFJ, Tang MW, Biemond BJ. Vaso-occlusive crisis and acute chest syndrome in sickle cell disease due to 2019 novel coronavirus disease (COVID-19). Am J Hematol 2020;95:725-6. https://doi.org/10.1002/ajh.25821. 
[18] Beerkens F, John M, Puliafito B, Corbett V, Edwards C, Tremblay D. COVID-19 pneumonia as a cause of acute chest syndrome in an adult sickle cell patient. Am J Hematol 2020;95:E154-6. https://doi.org/10.1002/ajh.25809.

[19] De Luna G, Habibi A, Deux JF, Colard M, Pham Hung d'Alexandry d'Orengiani AL, Schlemmer F, et al. Rapid and severe Covid-19 pneumonia with severe acute chest syndrome in a sickle cell patient successfully treated with tocilizumab. Am J Hematol 2020;95:876-8. https://doi.org/10.1002/ajh.25833.

[20] Allison D, Campbell-Lee S, Crane J, Vidanovic V, Webb S, Fraidenburg D, et al. Red blood cell exchange to avoid intubating a COVID-19 positive patient with sickle cell disease? J Clin Apher 2020;35:378-81. https://doi.org/10.1002/jca.21809.

[21] Justino CC, Campanharo FF, Augusto MN, Morais SC de, Figueiredo MS. COVID-19 as a trigger of acute chest syndrome in a pregnant woman with sickle cell anemia. Hematol Transfus Cell Ther 2020;42:2124. https://doi.org/10.1016/j.htct.2020.06.003.

[22] Quaresima M, Quaresima V, Naldini MM, Cirillo DM, Ferrari A, Mazzi A, et al. Clinical management of a Nigerian patient affected by sickle cell disease with rare blood group and persistent SARS-CoV-2 positivity. EJHaem 2020. https://doi.org/10.1002/jha2.53.

[23] Azerad M, Bayoudh F, Weber T, Minon J, Ketelslegers O, Hoyoux M, et al. Sickle cell disease and COVID-19: Atypical presentations and favorable outcomes. EJHaem 2020. https://doi.org/10.1002/jha2.74.

[24] Al-Hebshi A, Zolaly M, Alshengeti A, Al Qurainees G, Yamani S, Hamdan N, et al. A Saudi family with sickle cell disease presented with acute crises and COVID-19 infection. Pediatr Blood Cancer 2020;67. https://doi.org/10.1002/pbc.28547.

[25] Arlet JB, de Luna G, Khimoud D, Odièvre MH, de Montalembert M, Joseph L, et al. Prognosis of patients with sickle cell disease and COVID-19: a French experience. Lancet Haematol 2020;7:e632-4. https://doi.org/10.1016/S2352-3026(20)30204-0.

[26] McCloskey KA, Meenan J, Hall R, Tsitsikas DA. COVID-19 infection and sickle cell disease: a UK centre experience. Br J Haematol 2020;190:e57-8. https://doi.org/10.1111/bjh.16779.

[27] Balanchivadze N, Kudirka AA, Askar S, Almadhoun K, Kuriakose P, Fadel R, et al. Impact of COVID19 Infection on 24 Patients with Sickle Cell Disease. One Center Urban Experience, Detroit, MI, USA. Hemoglobin 2020. https://doi.org/10.1080/03630269.2020.1797775.

[28] Panepinto JA, Brandow A, Mucalo L, Yusuf F, Singh A, Taylor B, et al. Coronavirus Disease among Persons with Sickle Cell Disease, United States, March 20-May 21, 2020. Emerg Infect Dis 2020;26. https://doi.org/10.3201/eid2610.202792.

\section{List of figure and table legends:}

Figure 1. Chest Xray.

Table 1. Investigations.

Table 2. Literature review. 


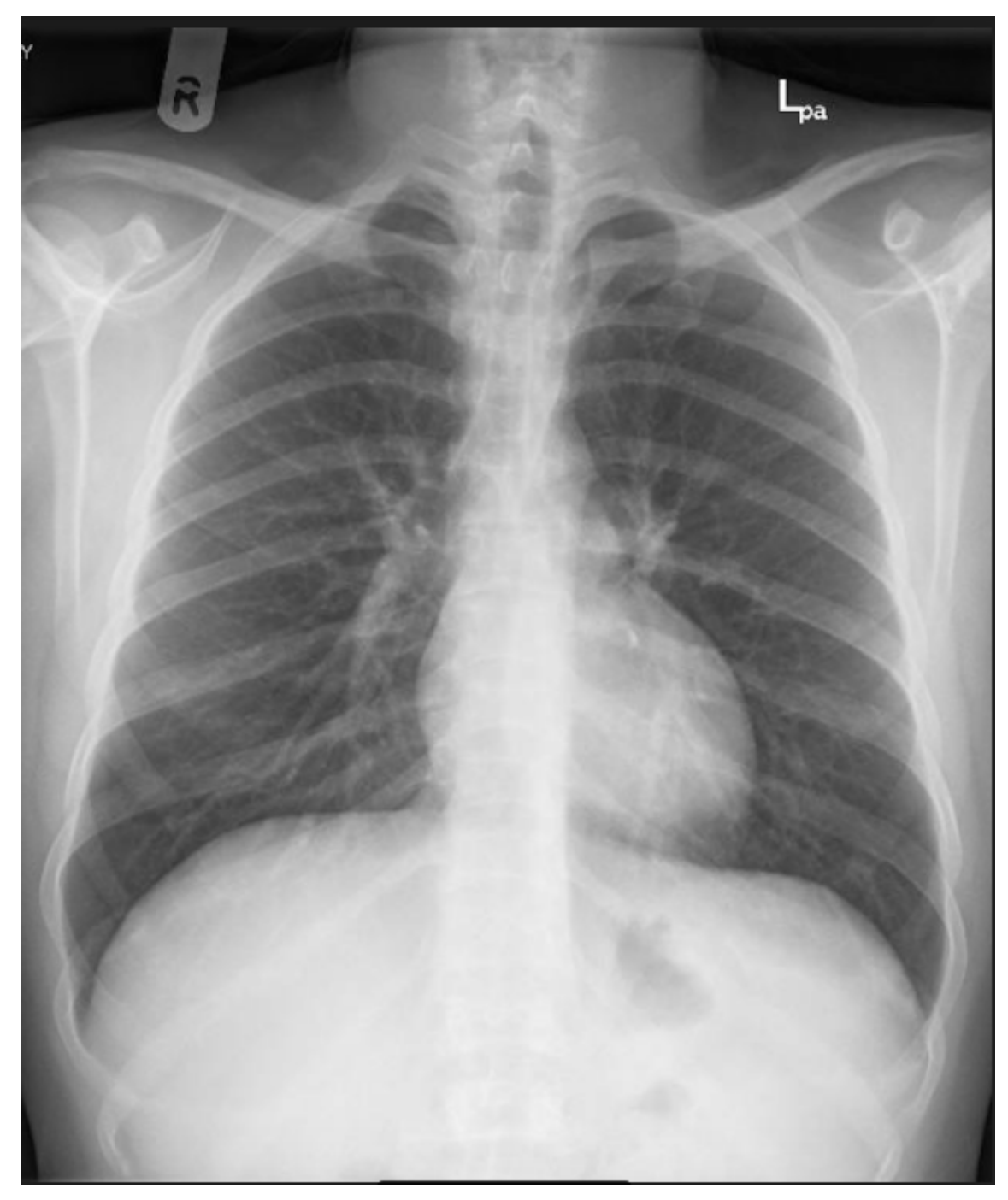

